\title{
An integrated analysis of agricultural water-use efficiency: A case study in the Heihe River Basin in Northwest China
}

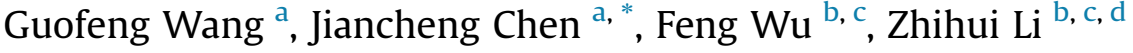 \\ a School of Economics and Management, Beijing Forestry University, Beijing 100083, China \\ ${ }^{\mathrm{b}}$ Institute of Geographic Sciences and Natural Resources Research, Chinese Academy of Sciences, Beijing 100101, China \\ ${ }^{\mathrm{c}}$ Center for Chinese Agricultural Policy, Chinese Academy of Sciences, Beijing 100101, China \\ d University of Chinese Academy of Sciences, Beijing, 100049, China
}

\section{A R T I C L E I N F O}

\section{Article history:}

Received 1 September 2015

Received in revised form

28 September 2015

Accepted 1 October 2015

Available online 23 October 2015

\section{Keywords:}

Water-use efficiency

Data envelopment analysis

Malmquist total productivity factor index

Tobit model

Heihe River Basin

\begin{abstract}
A B S T R A C T
The water-use efficiency has direct impacts on the water consumption of agriculture production and is vital to water conservation at both local and regional extent. The agricultural water-use efficiency is a critical indicator that reflects the effective water allocation and water productivity improvement among different agricultural sectors. Taking the Heihe River Basin as the case study area, this study explores the changing trajectories of agricultural water use based on the input-output data of 2003-2012, and estimates the water-use efficiency with Data Envelopment Analysis, Malmquist Total Productivity Index and the decomposition of total factor productivity. Further, the influence of driving factors on the wateruse efficiency is analyzed with the Tobit model. The research results indicate that the average agricultural water-use efficiency in different counties is all lower than 1 during 2003-2012, indicating that there is still improvement space in the agricultural water-use efficiency. In addition, there is obvious heterogeneity in the agricultural water-use efficiency among different counties, especially prior to 2009. The research results from the Tobit model indicate that agricultural investment and production, economic growth, industrial restructuring and agricultural plants structural adjustment have significant influence on the agricultural water-use efficiency. The research results can provide significant references for agricultural water-use management in the middle reaches of the Heihe River Basin and other similar regions in Northwest China.
\end{abstract}

๑) 2015 Elsevier Ltd. All rights reserved.

\section{Introduction}

Water resource is one of the most basic and critical elements for the living and production of human beings. The stable supply and efficient use of water resources play an important role in guaranteeing the sustainable socioeconomic development (Deng and Zhao, 2014; Singh et al., 2013; Zhao et al., 2010). UN World Water Development Report reveals that 66 countries with $21 \%$ of the world population would turn from moderate water shortage to severe situation by 2050, indicating great differences occur in global water distribution with severe water disequilibrium, which brings great challenge to the regional water supply (The United Nations World Water Development Report, 2014). As a country

\footnotetext{
* Corresponding author.

E-mail addresses: wanggf_simlab@163.com (G. Wang), Chenjc_bjfu@hotmail. com (J. Chen), lizh.12b@igsnrr.ac.cn (Z. Li).
}

with large population, China has been evaluated as one of the major countries with apparent unbalanced water supply and demand in the millennium ecosystem assessment report (Duraiappah et al., 2005). The global climate change leads to aggravated drying in specific areas (Duraiappah et al., 2005), threatening the water sustainability, which is vital for the global sustainable socioeconomic development. The utilization of water resource, especially agricultural water resource, plays an important role in the economic development (Deng et al., 2015; Jiang et al., 2014; Li et al., 2015a,b). Agricultural water consumption accounts for the largest proportion in China. According to the Statistics in Ministry of Water Resources of the People's Republic of China, 51.5\% of the cropland production depends on irrigation in 2014 (Deng and Zhao, 2014). Therefore, it is important to improve the agricultural water-use efficiency for the agricultural and extended economic development.

China will face the biggest challenge in agricultural water supply by 2050 (Deng et al., 2014). The water demand in China of 
cultivated land will be over 100 billion $\mathrm{m}^{3}$ to secure the food demand of approximately 1.5 billion people with the water supply only increase slightly in the foreseeable future, meanwhile a huge amount of water resource should be budgeted for restoring the destroyed ecology (Shi et al., 2014) and for the industrial sectors and other sectors, which will greatly constrain the water supply to the agricultural sectors (Shi et al., 2014; Wang et al., 2010).

There have been extensive researches on water resources, including water protection, effective utilization of water resources (Huang et al., 2013) and evaluation of water security (Chen et al., 2013) etc., particularly, the water-use efficiency has always been the core issue in different countries (Abu-Allaban et al., 2015; Kahil et al., 2015). At the early stage of the world development, water resource was regarded as "free commodity", while with the boom of global economy, the conflicts between water demand and supply have become fiercer, how to improve the water-use efficiency is becoming a very urgent task (Sun et al., 2014; Zhang and Wang, 2015). In UK, to improve the residents' living environment, the government has made great efforts to improve the water-use efficiency (Ruiz-Canales and Ferrández-Villena, 2015; Zhao et al., 2010). Experts in USA pointed out that the water price could improve the level of the water-use efficiency (Ruiz-Canales and Ferrández-Villena, 2015). In China, the government had carried out some related acts and measures to improve the water-use efficiency. For example, "Water Law of People's Republic of China", which was carried out in 2002, has given out some corresponding management policies for improving the industrial, agricultural and living water-use efficiency in terms of water resources allocation and water saving, such as the reduce, reuse and recycle of water.

The research on the agricultural water-use efficiency started in the middle of 20th century (Wang et al., 2001). Departments within UN specially established research institutions for water resource issues (Chen et al., 2015a; Kaminski et al., 2015; Yin et al., 2015). There have also been many scholars attempting to find out ways to improve the agricultural water-use efficiency. For example, Li et al. $(2015 a, b)$ reveals that water-use efficiency were uneven in the 31 provinces of China, with the irrigation efficiency in Hunan and Jiangsu Province (irrigation land) reaching only 60\% during 2005-2012. In addition, the average water-use efficiency was $30 \%$ in Northwest China in 2006, where only $3 \%$ of the water was effectively used and the rest water was wasted (Zhang et al., 2014). While, the water-use efficiency has improved significantly in some regions of Northwest China. For example, Minqin County, a typical agricultural area of Northwest China, has experienced three stages to achieve the comprehensive agricultural water use, during 2000-2003, the water-use efficiency proliferated from $22 \%$ to $42 \%$; during 2004-2008, while the water-use efficiency increased with $6 \%$ annually; and from 2009 to 2012 the efficiency finally reached $76 \%$.

China is suffering from severe water shortage, and the distribution of water resources are of high heterogeneous in space and time, which further aggravates the imbalance between water supply and demand (Hubacek et al., 2009;Wang, 2010). The contradiction between water supply and demand is more serious in the arid and semi-arid regions in Northwest China (e.g., Shaanxi, Qinghai, Gansu, Ningxia and Xinjiang), where water shortage has become the key constraint factor of economic development (Du et al., 2013; Liao and Dong, 2011). As a less developed and ecological fragile region, Northwest China has to face the contradictions between eco-environment protection and economic development (Li et al., 2013). The water use amount and water exploitation rate in Northwest China have increased rapidly with the booming of China's economy during the past decades. For example, the water exploitation rate has reached 50\% in Gansu Province and $70 \%$ in Xinjiang Province in 2009, which is much higher than the global average level (Zhao and Lian, 2015). Besides, the agriculture, which is the supporting industry of Northwest China, plays a key role in influencing the water use amount and water-use efficiency. Previous research shows that the water-use efficiency was low in most provinces in Northwest China, thus analyzing the influencing mechanism of agricultural water-use efficiency is vital to deal with the contradiction in the allocation of water resources among agriculture, industry and ecology in Northwest China.

There are various influencing factors of the water-use efficiency among different agricultural sectors. From a macro perspective, the industrial structure has strong impacts on agricultural water use, and the proportions of three main industries determine the allocation of water resources (Valta et al., 2015). In particular, the irrigation water-use efficiency is significantly affected by the demand for import-export business and the endowment of water resources (Dupoue et al., 2015), the proportion of canal water use, water price and the technology of water-saving irrigation (Binet et al., 2014) and institution for water utilization ( $\mathrm{Li}$ et al., 2015a,b). From the perspective of individual households, there are also a series of factors contributing to the differences in wateruse efficiency among regions, e.g., the age, agricultural labor force, irrigation area, ratio of agricultural income in the total income, level of awareness of water resource shortage, cost of water use, irrigation water source, and the implementation of water saving technology (Fischer et al., 2014). For example, previous research in Northwest and Southwest China suggested that the effects of influencing factors (e.g., irrigation area, length of the canal, water price and investment in irrigation) were different in the two regions due to the difference in the level of water shortage (Wang, 2010). In general, the regional water-use efficiency was determined by the coupling effect of nature and society. In the past, researches are mostly focused on the physical and engineering dimensions while with less studies at the socio-economic dimension. The investigation into the regional agricultural water-use efficiency is instructive for the understanding of the mutual feedback between agricultural water use and eco-environment. In this research, we are attempting to uncover the varying pattern of the regional agricultural water-use efficiency in the context of rapid industrialization, urbanization and climate change, and to propose the regulating factor for the improvement of regional agricultural water-use efficiency.

Previous researches on water resources in the Heihe River Basin mainly concentrated on the local water bearing capacity, water use strategies for water resources sustainability (Deng and Zhao, 2014; Nian et al., 2014; Wang et al., 2015; Wu et al., 2014b), which have pointed out that the eco-footprint of agriculture was much higher than that of other sectors (Wu et al., 2014c; Zhang et al., 2012). In this study, the Data Envelopment Analysis (DEA) and Malmquist Total Factor Productivity Index were first used to calculate the agricultural water-use efficiency and total factor productivity (TFP) growth rate in the agricultural production area of the Heihe River Basin from 2003 to 2012. Then the Tobit model was used to analyze the driving factors of the agricultural water-use efficiency. The results of this study can provide important references for the sustainable use of water resources and improvement of the agricultural water-use efficiency in the Heihe River Basin and other similar regions.

\section{Study area}

The Heihe river originates from Qilian Mountain in the northeast of Qinghai-Tibet Plateau, and goes through Qinghai, Gansu and Inner Mongolia (Nian et al., 2014; Wang et al., 2015). Endowed with the continental dry climate, it is characterized with low rainfall, strong evaporation, and serious water resource deficiency (Wu 
et al., 2014a). We choose eight counties of Gansu Province in the Heihe River Basin as the study area, including Ganzhou, Gaotai, Shandan, Minle, Linze, Jinta, Sunan and Suzhou (Fig. 1), with featured agriculture and animal husbandry development, which are the main agriculture production region. The cultivated land area in the study area was $2.66 \times 10^{5} \mathrm{~m}^{2}$, accounting for $9.29 \%$ of Gansu's total area, with the agriculture production reached $1.24 \times 10^{9} \mathrm{~kg}$ in 2012 , which accounted for $11.1 \%$ of Gansu's total grain production. In addition, in the Heihe River Basin, Zhangye city was regarded as the National Important Maize Seed Base, which accounts for $26.8 \%$ of the national maize seed planting area of China in 2014 (Wu et al., 2014a).

The economic development in the basin largely depends on agricultural production, which is highly water-consuming. Statistics showed that agriculture consumes the largest part of water resources in the basin, reaching about $92.31 \%$ of the total, among which the irrigation water accounts for $89.73 \%$ in 2011 (Fig. 2). The water diversion policy has been complemented in the Heihe River Basin since 2000, which constrains the water use for agricultural production in the middle reaches. In this sense, it is urgent to improve the agricultural water-use efficiency in this area.

\section{Data and methodology}

\subsection{Data and processing}

A set of panel data at the county level was constructed to analyze the dynamic changes in the agricultural water-use efficiency during 2003-2012. As to the variables used in the DEA model, the agricultural production was taken as the output variable, while the input factors included the agricultural fixed investment of past years (depreciated value), agricultural labor force and agricultural water consumption amount (Table 1). The driving factors of the agricultural water-use efficiency were selected with reference to the relevant researches and required to be absent in the DEA calculation. The data on water consumption was derived from Zhangye Water Bureau, and the other variables were derived from the database of the Center of Chinese Agricultural Policy at the Chinese Academy of Sciences.

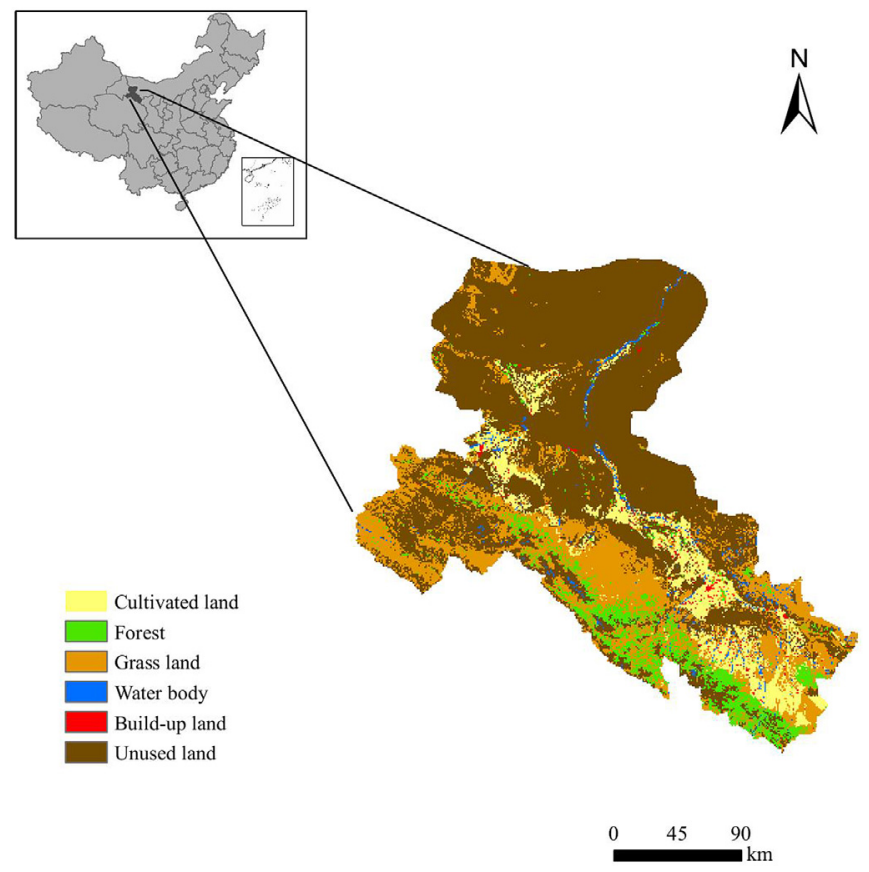

Fig. 1. Location of the study area in the Heihe River Basin.

\subsection{Agricultural water-use efficiency assessment with DEA}

Agricultural water-use efficiency refers to the ratio of the minimum water consumption which can be realized theoretically to the actual water consumption with the predefined input and output level (FAO, 1997). There are a number of methods to analyze the agricultural water-use efficiency, and the most widely used ones were the parametric method the Stochastic Frontier Analysis (SFA) and the non-parametric method DEA (Linm and Tseng, 2005). DEA analysis aims to establish a non-parametric frontier by using the data. The DEA was chosen to measure the agricultural water-use efficiency in this study. Aiming to analyze how to improve the water-use efficiency with the fixed water supply amount, we utilized input oriented DEA. When the value of efficiency equals to 1 , it means the decision unit is on the production frontier, the actual production value has no difference with the possible maximum value. When the efficiency is lower than 1 , it implies that there is still improvement potential for the decision unit. In this research, when the value of the efficiency reaches 1 , the water-use efficiency of this decision unit would be higher (Branda, 2015; Chen et al., 2015b). Suppose there are $N(=1,2,3, \ldots 8)$ decision units putting in $I(=1,2,3 \ldots)$ factors at $T(=1,2,3 \ldots)$ time periods, then $J(=1,2$, 3...) kinds of outputs will be generated. When referring to the input-output index, we used $X$ and $Y$ to represent the input and output, then the input-output index of $N$ counties (which equal to the decision unit) during different periods can be marked as $x_{i, n}^{t}$ and $y_{i, n}^{t}$. If we set $x_{i}=\left(x_{1 n}, x_{2 n}, \ldots, x_{I n}\right), y_{j}=\left(y_{1 n}, y_{2 n}, \ldots, y_{J n}\right)$, the model is specified as follows,

$$
\left\{\begin{array}{l}
\min \theta=V_{D} \\
\sum_{n=1}^{8} \lambda_{j} X_{i}+S^{-}=\theta X_{0} \\
\sum_{n=1}^{8} \lambda_{j} Y_{j}+S^{+}=Y_{0} \\
\lambda_{j} \geq 0, N=1, \ldots, 8 \\
S^{-} \geq 0, S^{+} \geq 0
\end{array}\right.
$$

where, $\theta(0<\theta<1)$ is the comprehensive technical scale efficiency. $\lambda_{j}$ is the weighting variable, $S^{-}\left(S^{-} \geq 0\right)$ is the slack variable, $S^{+}\left(S^{+} \geq 0\right)$ is the surplus variable and $\varepsilon$ is the Archimedes infinitesimal. The equation above is the DEA model based on constant scale returns, if $\theta=1$, it means the county reaches the optimal situation of water use on the frontier.

\subsection{Analysis on productivity change using Malmquist total factor productivity index}

The Malmquist Total Factor Productivity index was utilized to compute the TFP growth rate and to analyze the improvement in

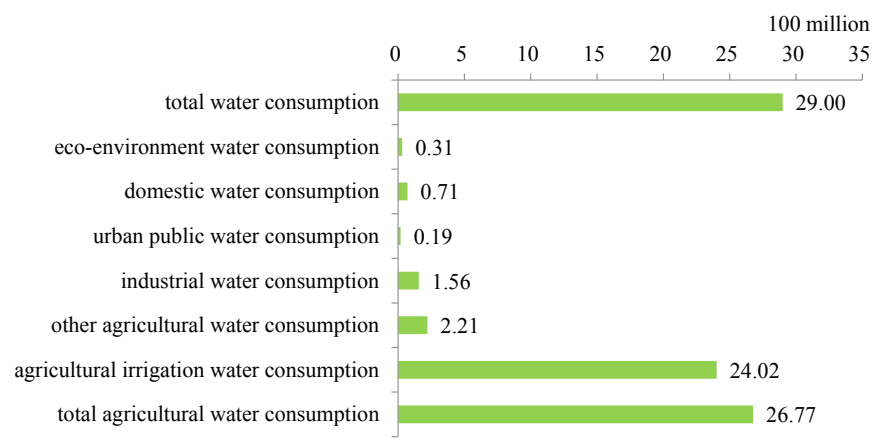

Fig. 2. Water consumption of different sectors in the Heihe River Basin in 2011. 
Table 1

Summary of the variables used in the DEA model.

\begin{tabular}{|c|c|c|c|c|}
\hline Variable & Unit & Observation & Mean & Std. Dev \\
\hline Agricultural production & Ton & 80 & $1.98 \times 10^{9}$ & $2.49 \times 10^{9}$ \\
\hline Agricultural fixed investment of past years & Yuan* & 80 & $2.19 \times 10^{9}$ & $2.91 \times 10^{9}$ \\
\hline Agricultural labor force & Person & 80 & $1.48 \times 10^{5}$ & $9.48 \times 10^{4}$ \\
\hline Agricultural water consumption amount & $\mathrm{m}^{3}$ & 80 & $3.72 \times 10^{8}$ & $2.03 \times 10^{9}$ \\
\hline
\end{tabular}

Note *: Yuan at the price of 2002.

technical efficiency and technical change (Afsharian and Ahn, 2015; Arabi et al., 2015; Fan et al., 2015). Supposing $D_{c}^{t}\left(x_{t}, y_{t}\right)$ are the distance functions, calculation of the Malmquist Total Factor Productivity index based on the period $t$ and $t+1$ and calculation of comprehensive technical efficiency change are as follows,

$$
\begin{aligned}
& M\left(x_{t}, y_{t}, x_{t+1}, y_{t+1}\right)=E C \times T C \\
& =\left[\frac{D_{t}^{c}\left(x_{t+1}, y_{t+1}\right)}{D_{t}\left(x_{t}, y_{t}\right)} \times \frac{D_{c}^{t+1}\left(x_{t+1}, y_{t+1}\right)}{D_{c}^{t+1}\left(x_{t}, y_{t}\right)}\right]^{\frac{1}{2}} \\
& E C=M_{t}\left(x^{t}, y^{t}, x^{t+1}, y^{t+1}\right)=\frac{D_{t}^{c}\left(x_{t+1}, y_{t+1}\right)}{D_{t}\left(x_{t}, y_{t}\right)} \\
& T C=M_{t+1}\left(x^{t}, y^{t}, x^{t+1}, y^{t+1}\right)=\frac{D_{c}^{t+1}\left(x_{t+1}, y_{t+1}\right)}{D_{c}^{t+1}\left(x_{t}, y_{t}\right)}
\end{aligned}
$$

The Malmquist Total Factor Productivity index is widely used to divide the rate of TFP change into technical efficiency change (EC) and technical change (TC). The technological development will bring about changes in the production frontier, and EC is the changes of TFP growth caused by the changes of production frontier within a certain time period. Technical efficiency refers to the changes in TFP caused by efficiency change of technology itself.

\subsection{Driving forces of agricultural water-use efficiency using tobit model}

The Tobit model shows superiority to the ordinary least squares regression when there are both continuous variables and discrete variables. In this study, the agricultural water-use efficiency ranges from 0 to 1 , therefore the Tobit model is applied to analyze the effects of driving factors on agricultural water-use efficiency, which is as follows,

$y_{i}^{*}=\beta_{0}+\sum_{j=1}^{k} \beta_{j} x_{i j}+\varepsilon_{i}$

$y_{i}= \begin{cases}0, & \text { if } y_{i}^{*} \in(-\infty, 0] \\ y_{i}^{*}, & \text { if } y_{i}^{*} \in(0,1] \\ 1, & \text { if } y_{i}^{*} \in(1,+\infty)\end{cases}$

where, $y_{i}$ represents the agricultural water-use efficiency in the $i$ th county, and $x_{i j}$ includes various factors influencing the agricultural water-use efficiency.

\section{Results and analysis}

\subsection{Changes of the agricultural water-use efficiency and TFP rate}

The results reveal that distinct disparities exist among different areas with regard to agricultural water-use efficiency. Fig. 3 shows that the highest agricultural water-use efficiency appears in Ganzhou, with the value higher than 0.9 for most years, while the agricultural water-use efficiency in Jinta is comparatively low, with the values of many years lower than 0.5 during 2003-2012. In terms of the changes in agricultural water-use efficiency, disparities also still exist in different counties, with Ganzhou, Minle and Linze showing slight changes, while Jinta, Sunan and Suzhou presenting relatively considerable fluctuations. Specifically, the agricultural water-use efficiency keeps high in Minle and Linze, whereas obvious declines occur since 2012, which is synchronous with the vegetables and livestock production development. In 2012, Minle and Linze produced a large variety of vegetables which may induce water loss. In Sunan, the agricultural water-use efficiency is lower than 0.5 before 2009, however, it improved markedly and approximated to the level of other counties during 2010-2012. Suzhou experienced the fluctuations with the rising at the beginning, declining in the middle and increasing again. In general, the trajectory of the agricultural water-use efficiency change is consistent with the industrial adjustment, especially the development of cultural industries.

The results based on Malmquist Total Factor Productivity Index showed a fluctuated variation pattern for TFP growth rate (Fig. 4), with its value more than 1 during 2003-2004, 2006-2007, 2009-2010 and 2011-2012, less than 1 in 2004-2005, 2005-2006, 2008-2009 and 2010-2011, no obvious change during 2007-2008.

\subsection{Impacts of driving factors on the agricultural water-use efficiency}

Undoubtedly, agricultural water-use efficiency changes are attributed to various physical and socioeconomic factors as well as their coupling effects. In this study, we focus on the influences of socioeconomic factors and choose a series of indicators, such as average net income of each rural resident representing the rural resident estates, change rate of investment in fixed assets, gross domestic product (GDP) representing economic growth, the proportion of the agricultural industry value, the second industry value to GDP representing the industrial structure, the planting area of the corn, wheat, effective irrigation area, disaster area and other crops representing the planting structure adjustment (Table 2).

There is a remarkable variation in the industrial structures in different counties, thus in the proportions of the output value of the three industries in GDP. In 2012, Suzhou had the lowest agricultural output value proportion, whereas Gaotai exhibited the highest agricultural output value proportion (Fig. 5).

The average net income of each rural resident $(+0.08 \%)$ has positive impacts on the agricultural water-use efficiency. This is because higher net income enables farmers to use better agricultural facilities, e.g., irrigation machines and equipment, which can consequently improve the agricultural water-use efficiency.

Economic growth identified by the GDP at the local extent $(-0.07 \%)$ will have negative effects on the agricultural water-use efficiency. It is justified that the growth of GDP is largely attributed to the development of industrial and service sectors whereas 


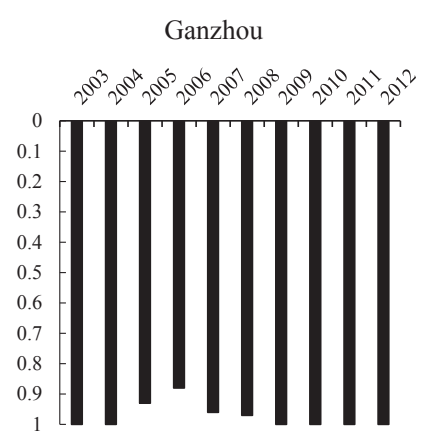

(a)

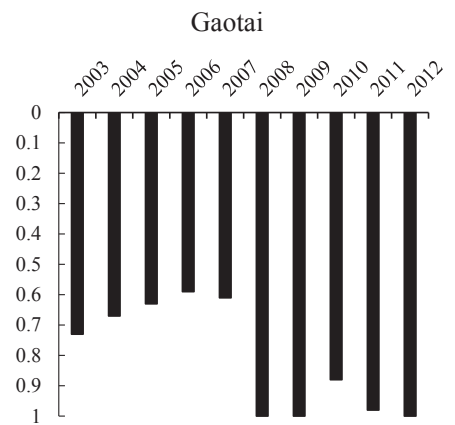

(c)
Jinta

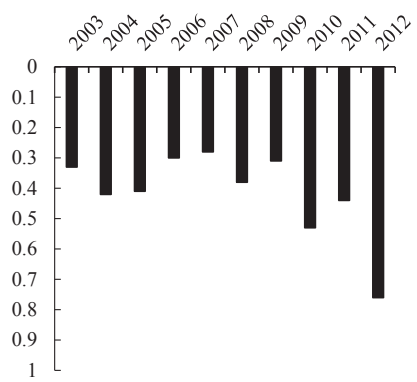

(b)

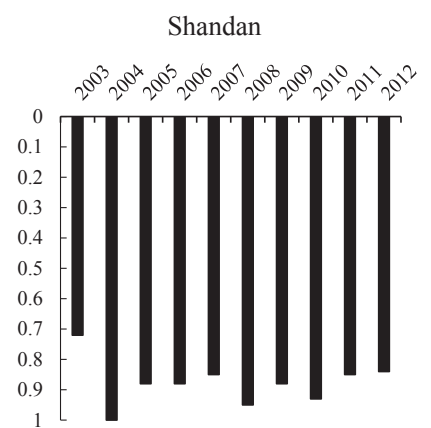

(d)

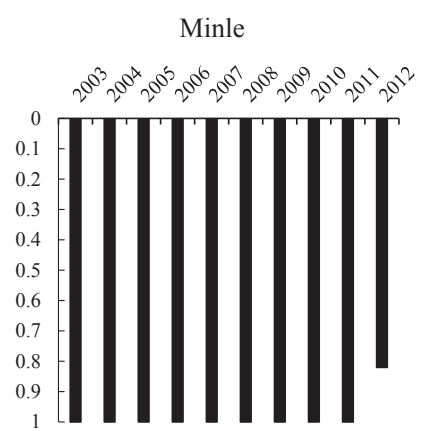

(e)

(g)
Sunan

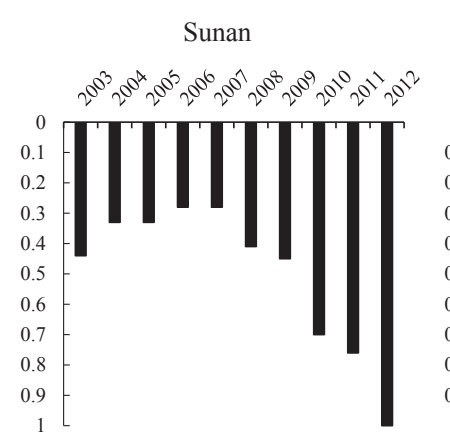

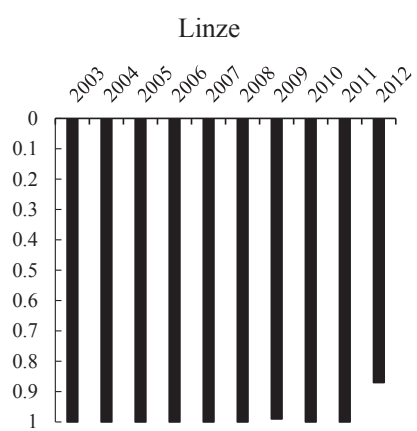

(f)

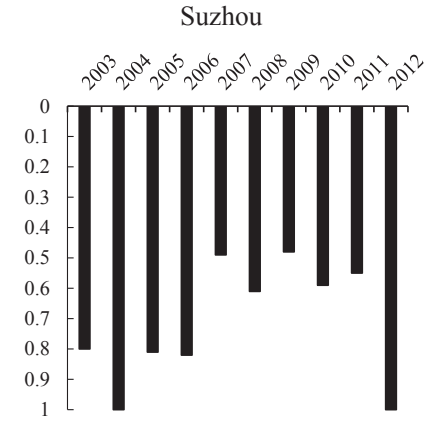

(h)

Fig. 3. County level agricultural water-use efficiency in the Heihe River Basin during 2003-2012.

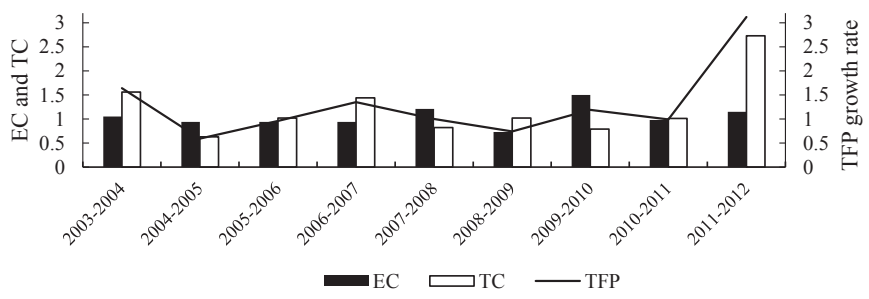

Fig. 4. TFP growth rates and Malmquist decomposition results in agricultural production areas in the Heihe River Basin. (results for the whole study area where EC refers to technical efficiency change and TC refers to technical change).

agricultural sectors contributed a confined proportion, indicating the possibility that increasing the water consumption lowers the agricultural water-use efficiency.

The proportion of primary industry $(+0.03 \%)$ has positive effects. Coupled with the economic development, the role of agriculture among the three industries will be gradually undermined, and it is the same case for the role of agriculture in improving the water-use efficiency. In order to promote the development of agriculture, the local people will make more investment in the agricultural irrigation infrastructure, which can consequently improve the agricultural water-use efficiency.

The wheat planting area $(+0.22 \%)$ and other crops planting area $(+0.16 \%)$ had significant positive effects on the agricultural wateruse efficiency. Besides, the coefficient of the wheat planting area is larger than that of other crops, indicating that the changes of wheat planting area will have more powerful influence on agricultural water-use efficiency. It is feasible to improve the agricultural water-use efficiency by enlarging the planting area of wheat.

The results of the Tobit model showed that increasing the investment, modification on plantation structure and adjustment on industrial structure contributed to improving the agricultural water-use efficiency. Increasing $10 \%$ fixed assessment investment is capable of improving agricultural water-use efficiency by $0.1 \%$; expanding $1 \%$ of the wheat area can improve agricultural water-use efficiency by $0.22 \%$; As a result, during upgrading the industrial structure, it guarantee the agricultural water consumption and avoid low efficiency and waste.

\section{Conclusions and discussions}

In this study, taking the Heihe River Basin in the northwest China as a case study area, we have applied an integrated model to analyze the agricultural water-use efficiency. The importance of improving the agricultural water-use efficiency has been justified, the results revealed that the strengthening of agricultural infrastructure and the increasing the percentage of agriculture and the planning structure both have positive effect on the improvement of agricultural water-use efficiency. But the influence from technological advancement is more powerful. In China, there are more than 459 irrigated areas with different irrigation technique levels, with a considerable number having the problem of high crop water-use efficiency but low agricultural water-use efficiency. In this sense, the accurate measurement on the agricultural water-use efficiency and its driving factors is conductive to the efficient water resource utilization.

Improving water-use efficiency is a complex process, in which the systematic and regional perspectives are in an anticipation to be integrated to seek the water saving scheme in arid areas. Water conservation in crop and industry is suggested to be combined to improve the regional agricultural water-use efficiency. At regional level, regulations on improving agricultural water use security by improving agricultural water-use efficiency are expected, and the zoning and categorization approaches are also advised to be 
Table 2

Tobit regression results on the impacts of driving factors on agricultural water-use efficiency.

\begin{tabular}{|c|c|c|c|}
\hline Variables & Coefficient & Standard deviation & 95\% Confidence interval \\
\hline corn planting area & $0.003(-0.06)$ & 0.05 & $(-0.11,0.10)$ \\
\hline wheat planting area & $0.22^{* * *}(8.33)$ & 0.03 & $(0.17,0.27)$ \\
\hline other crops planting area & $0.16^{* * *}(3.23)$ & 0.05 & $(0.06,0.26)$ \\
\hline average net income of each rural resident & $0.08^{* * *}(3.57)$ & 0.02 & $(0.03,0.12)$ \\
\hline effective irrigation area & $-0.07^{* * *}(2.90)$ & 0.02 & $(-0.12,-0.02)$ \\
\hline disaster area & $0.06^{* * *}(2.35)$ & 0.03 & $(0.009,0.11)$ \\
\hline GDP & $-0.04^{* *}(-1.61)$ & 0.02 & $(-0.09,0.02)$ \\
\hline proportion of primary industry & $0.03(1.23)$ & 0.02 & $(0.06,0.01)$ \\
\hline proportion of secondary industry & $-0.06(-2.58)$ & 0.02 & $(-0.11,0.01)$ \\
\hline change rate of investment in fixed assets & $0.01^{* *}(0.80)$ & 0.02 & $(-0.02,0.05)$ \\
\hline Constant & $0.78(45.77)$ & 0.02 & $(0.74,0.81)$ \\
\hline
\end{tabular}

Note: t statistics in parentheses; ${ }^{*}$ significant at $10 \% ;{ }^{* *}$ significant at $5 \%$; ${ }^{* * *}$ significant at $1 \%$.

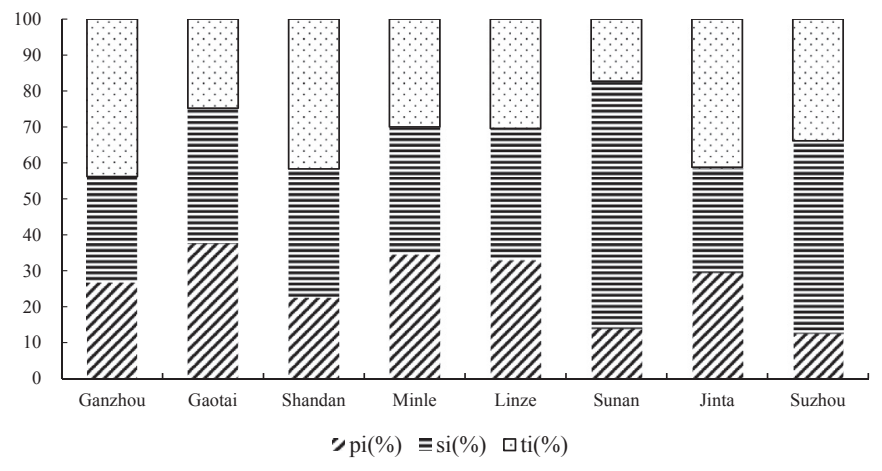

Fig. 5. Proportions of three industries in 2012 (pi, si, ti refers to the proportion of the output value of the primary industry, second industry and tertiary industry in local GDP, respectively).

implemented in precision management on agricultural water consumption in arid areas.

\section{Conflict of interests}

The authors declare that there is no conflict of interests regarding the publication of this article.

\section{Acknowledgment}

This research was financially supported the major research plan of the National Natural Science Foundation of China (Grant No. 91325302; 91425303) and the funding support from the Institute of Geographic Sciences and Natural Resources Research, Chinese Academy of Sciences (Grant No. 2012ZD008).

\section{References}

Abu-Allaban, M., El-Naqa, A., Jaber, M., et al., 2015. Water scarcity impact of climate change in semi-arid regions: a case study in Mujib basin, Jordan. Arab. J. Geosci. 8, 951-959.

Afsharian, M., Ahn, H., 2015. The overall Malmquist index: a new approach for measuring productivity changes over time. Ann. Oper. Res. 226, 1-27.

Arabi, B., Munisamy, S., Emrouznejad, A., 2015. A new slacks-based measure of Malmquist-Luenberger index in the presence of undesirable outputs. Omega 51, 29-37.

Binet, M.E., Carlevaro, F., Paul, M., 2014. Estimation of residential water demand with imperfect price perception. Environ. Resour. Econ. 59, 561-581.

Branda, M., 2015. Diversification-consistent data envelopment analysis based on directional-distance measures. Omega 52, 65-76.

Chen, J., Song, M., Xu, L., 2015a. Evaluation of environmental efficiency in China using data envelopment analysis. Ecol. Indic. 52, 577-583.

Chen, S., Zhou, Z., Andersen, M.N., Hu, et al., 2015b. Tomato yield and water use efficiency-coupling effects between growth stage specific soil water deficits. Acta Agric. Scand. Sect. B Soil Plant Sci. 65, 460-469.
Chen, Z., Wang, H., Qi, X., 2013. Pricing and water resource allocation scheme for the south-to-north water diversion project in China. Water Resour. Manag. 27, $1457-1472$.

Deng, X., Shi, Q., Zhang, Q., et al., 2015. Impacts of land use and land cover changes on surface energy and water balance in the Heihe River Basin of China, 2000-2010. Phys. Chem. Earth Parts A/B/C 79-82, 2-10.

Deng, X., Zhao, C., 2014. Identification of water scarcity and providing solutions for adapting to climate changes in the Heihe River Basin of China. Adv. Meteorol.

Deng, X., Zhang, F., Wang, Z., et al., 2014. An extended input output table compiled for analyzing water demand and consumption at country level in China. Sustainability 6, 3301-3320.

Du, C., Y, Y., J, J., 2013. Risk evaluation of water resources exploration and utilization in western China. China Popul. Resour. Environ. 23, 59-66.

Dupoue, A., Brischoux, F., Angelier, F., et al., 2015. Intergenerational Trade-off for Water May Induce a Motherer. F., DeNardo, D.F., Wright, C.D., Lourdais, O., 2015. Intergenerational tradeulatio 414-422.

Duraiappah, A.K., Naeem, S., Agardy, T., et al., 2005. Ecosystems and Human Wellbeing: Biodiversity Synthesis. Island Press, Washington, DC.

Fan, M., Shao, S., Yang, L., 2015. Combining global Malmquist-Luenberger index and generalized method of moments to investigate industrial total factor $\mathrm{CO}_{2}$ emission performance: a case of Shanghai (China). Energy Policy 79, 189-201.

Fischer, N.C., Shamah-Levy, T., Mundo-Rosas, V., et al., 2014. Household food insecurity is associated with anemia in adult Mexican women of reproductive age. J. Nutr. 144, 2066-2072.

Huang, J., Zhan, J., Yan, H., et al., 2013. Evaluation of the impacts of land use on water quality: a case study in the Chaohu Lake basin. Sci. World J.

Hubacek, K., Guan, D., Barrett, J., et al., 2009. Environmental implications of urbanization and lifestyle change in China: ecological and water footprints. J. Clean. Prod. 17, 1241-1248.

Jiang, L., Wu, F., Liu, Y., Deng, X., 2014. Modeling the impacts of urbanization and industrial transformation on water resources in China: an integrated hydroeconomic CGE analysis. Sustainability 6, 7586-7600.

Kahil, M.T., Dinar, A., Albiac, J., 2015. Modeling water scarcity and droughts for policy adaptation to climate change in arid and semiarid regions. J. Hydrol. 522, 95-109.\%@0022-1694.

Kaminski, K.P., Kørup, K., Kristensen, K., et al., 2015. Contrasting water-use efficiency (WUE) responses of a potato mapping population and capability of modified ball-berry model to predict stomatal conductance and WUE measured at different environmental conditions. J. Agron. Crop Sci. 201, 81-94.

Li, B., Chen, Y., Shi, X., et al., 2013. Temperature and precipitation changes in different environments in the arid region of northwest China. Theor. Appl. Climatol. 112, 589-596.

Li, W., Zhang, B., Li, R., et al., 2015a. Favorable alleles for stem water-soluble carbohydrates identified by association analysis contribute to grain weight under drought stress conditions in wheat. Plos One 10.

Li, Z., Deng, X., Wu, F., Hasan, S.S., 2015b. Scenario analysis for water resources in response to land use change in the middle and upper reaches of the Heihe River Basin. Sustainability 7, 3086-3108.

Liao, H.,C., Dong, Y.M., 2011. Utilization efficiency of water resources in 12 western provinces of China based on the DEA and Malmquist TFP index. Resour. Sci. 33, 273-279.

Linm, L., Tseng, L., 2005. Application of DEA and SFA on the Measurement of Operating Efficiencies for 27 International Container Ports, pp. 592-607.

Nian, Y., Li, X., Zhou, J., Hu, X., 2014. Impact of land use change on water resource allocation in the middle reaches of the Heihe River Basin in northwestern China. J. Arid Land 6, 273-286.

Ruiz-Canales, A., Ferrández-Villena, M., 2015. New proposals in the automation and remote control of water management in agriculture: agromotic systems. Agric. Water Manag. 1-3.

Shi, Q., Chen, S., Shi, C., et al., 2014. The impact of industrial transformation on water use efficiency in northwest region of China. Sustainability 7, 56-74.

Singh, R.B., Gahlot, S., Singh, A., 2013. Ecohydrological Perspectives of Declining Water Sources and Quality in Traditional Water Bodies in Delhi. Proc. H 4 , pp. 361-368. 
Sun, C., Zhao, L., Zou, W., et al., 2014. Water resource utilization efficiency and spatial spillover effects in China. J. Geogr. Sci. 24,771-788.\%@ 1009-1637X.

The United Nations World Water Development Report 2015: Water for a Sustainable World, P, 2014. United Nations World Water Development Report. Unesco Pub.

Valta, K., Kosanovic, T., Malamis, D., et al., 2015. Overview of water usage and wastewater management in the food and beverage industry. Desalin. Water Treat. 53, 3335-3347.

Wang, X., Yang, H., Shi, M., et al., 2015. Managing stakeholders' conflicts for water reallocation from agriculture to industry in the Heihe River Basin in northwest China. Sci. Total Environ. 505, 823-832.

Wang, X.Y., 2010. A comparative study of irrigation water efficiency of farmers based on DEA and SFA- by using survery data from northwest China. China Rural Water Hydropower 8-13.

Wang, Y.-B., Wu, P., Zhao, X., Li, J., 2010. Development tendency of agricultural water structure in China. Chin. J. Eco-Agric. 18, 399-404.

Wang, H., Zhang, L., Dawes, W.R., et al., 2001. Improving water use efficiency of irrigated crops in the North China Plain - measurements and modelling. Agric. Water Manag. 48, 151-167.

Wu, F., Zhan, J., Güneralp, I., 2014a. Present and future of urban water balance in the rapidly urbanizing Heihe River Basin, northwest China. Ecol. Model.
Wu, F., Zhan, J., Zhang, Q., Sun, Z., Wang, Z., 2014b. Evaluating impacts of industrial transformation on water consumption in the Heihe River Basin of northwest China. Sustainability 6, 8283-8296.

Wu, L., L, Z., R, Z., et al., 2014c. Water saving, coordinated and sustainable development of agriculture in the Heihe River Basin. J. of Desert Res. 34, 938-942.

Yin, W.Y., A, Z., Chai, O., et al., 2015. Wheat and maize reply-planting with straw covering increases water use efficiency up to $46 \%$. Agron. Sustain. Dev. 35, $815-825$.

Zhang, J., Wang, L., 2015. Assessment of water resource security in Chongqing city of China: what has been done and what remains to be done? Nat. Hazards 75, 2751-2772.

Zhang, J.Z., D.M, Zhang, R.,L., 2012. Dynamic characteristics of water footprint and water resources carrying capacity in Heihe River Basin during 2004-2010. J. of Desert Res. 32 (6)

Zhang, Q., Liu, B., Zhang, W., et al., 2014. Assessing the regional spatio-temporal pattern of water stress: a case study in Zhangye city of China. Phys. Chem. Earth Parts A/B/C 79-82, 20-28.

Zhao, K., Lian, H., 2015. Bayesian tobit quantile regression with single-index models. J. Stat. Comput. Simul. 85, 1247-1263.

Zhao, S., Liu, S., Yin, R., Li, Z., et al., 2010. Quantifying terrestrial ecosystem carbon dynamics in the Jinsha watershed, Upper Yangtze, China from 1975 to 2000. Environ. Manag. 45, 466-475. 